\title{
Identification of Potential Off-targets of Chemotherapeutic agent Sorafenib: A Molecular Docking Approach
}

\author{
Tammanna R. Sahrawat* \& Parul Chawla \\ Centre for System Biology \& Bioinformatics, UIEAST, Panjab University, Chandigarh, India \\ *Corresponding author - tammanna@pu.ac.in
}

\begin{abstract}
Keywords: Drug off-targets, cancer, molecular docking, receptor tyrosine kinases, Chemotherapeutic agent, Sorefenib
\end{abstract}

\begin{abstract}
B-Raf is a multi- drug target serine/threonine protein kinase, involved in the transduction of mitogenic signals from the cell membrane to the nucleus. Mutated B-Raf causes overactive downstream signaling via MEK and ERK, leading to excessive cell proliferation and survival, independent of growth factors causing cancers such as Pancreatic carcinoma. A novel biaryl urea- Sorafenib, is a potent inhibitor of Raf-1 that has been approved for the treatment of a number of cancers including pancreatic cancer. The present investigation was designed to identify the potential off-targets of Sorafenib which could be responsible for its reported undesirable side effects. Molecular docking was used to test the efficacy of structural analogs of Sorafenib against B-Raf using FlexX and it was found that the analog with CID:10151557 had a high potency with minimum number of clashes, low lipophilic score and high match score, similar to Sorafenib. To identify the potential off-target/s of Sorafenib, macromolecular surface similarity detection software MEDIT SA MED-SuMo was used and the results obtained were validated through literature. The possible off-targets obtained belonged to the family of protein tyrosine kinases i.e. VEGFR-2, VEGFR-3, platelet-derived growth factor receptor beta, Flt-3, and c-KIT, each of which were docked with Sorafenib. Based on high docking scores and similarity with B-Raf for its binding site interacting residues, it was concluded that Vascular endothelial growth factor tyrosine kinase receptor (VEGFR) is a potential off-target of anti-cancer chemotherapeutic agent Sorafenib.
\end{abstract}

\section{INTRODUCTION}

Pancreatic carcinoma falls into two major categories: (1) cancers of the endocrine pancreas (the part that makes insulin) are called "islet cell" or "pancreatic neuroendocrine" cancers and (2) cancers of the exocrine pancreas (the part that makes enzymes). Islet cell cancers are rare and typically grow slowly compared to exocrine pancreatic cancers. Cancers of the exocrine pancreas develop from the cells that line the system of ducts that deliver enzymes to the small intestine and are commonly referred to as pancreatic adenocarcinomas. Adenocarcinoma of the pancreas comprises $95 \%$ of all pancreatic ductal cancers. The exact cause of pancreatic cancer is unknown, though it is more common in people with long-term inflammation of the pancreas (chronic pancreatitis) $[1,2]$.

B-Raf is a critical protein in pancreatic cancer being a member of the RAF family, coded by the $B R A F$ gene. The RAF family of proteins includes 3 isoforms: A-Raf, B-Raf and C-Raf [3]. While each isoform plays a role in the RAS-RAF pathway, B-Raf is the main activator of MEK, a pathway responsible for normal cell growth, differentiation, and survival [4]. Two major pathways subsequently activated by RTK's are the phosphatidylinositol 3-kinase (PI3K)/AKT and the mitogen-activated protein kinases ERK [5].The RAF kinase family serves as a central intermediate to relay signals from RAS to ERK. B-Raf is a serine-threonine-specific protein kinase that is mutated in $2 \%$ of human cancers- renal cell carcinoma and hepatocellular carcinoma [6]. Figure 1 shows KEGG pathway database result for K-Ras activated Raf-ERK pathway in pancreatic ductal cell. 


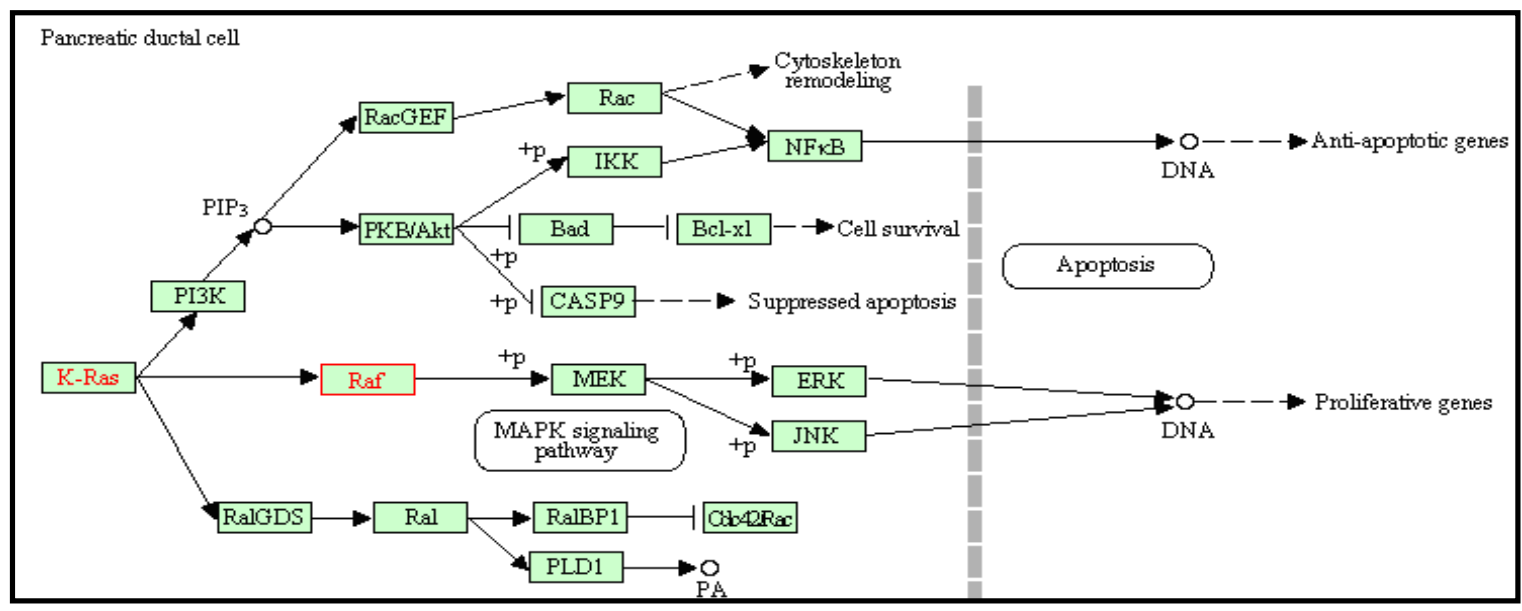

Fig 1: K-Ras activated Raf-ERK pathway in pancreatic ductal cell from KEGG Database.

Preclinical studies demonstrate that mutations in the $B R A F$ gene allow for B-Raf to signal independently of upstream cues [7]. As a result, mutated B-Raf causes overactive downstream signaling via MEK and ERK [8]. This leads to excessive cell proliferation and survival, independent of growth factors [9].

The present study was designed to identify the possible off-targets for the drug Sorafenib that binds to the protein B-Raf. The drug Sorafenib [CID 216239] has been approved for pancreatic and renal cell carcinoma [10-12]. It is an orally active biarylureic multi-kinase inhibitor originally developed to block the ERK pathway by targeting Raf-kinases, such as Raf-1 and B-Raf with effects on tumor-cell proliferation and tumor angiogenesis [13]. A number of structural analogs of Sorafenib have been listed in PubChem [14]. Identification of a binding site similar to that of B-Raf in other proteins would suggest the likelihood of Sorafenib to bind to these similar target/s. This target hopping would be a strong rational evidence for identification of possible off-target/s of the chemotherapeutic drug-Sorafenib.

\section{MATERIAL AND METHODS}

\section{(i) Protein Retrieval:}

The three dimensional structure of the complex of wild type B-Raf and BAY 439006 [15] was obtained from the Protein Data Bank (PDB ID: 1UWH).

(ii) Retrieving B-Raf Inhibitors:

Inhibitors against pancreatic cancer target B-Raf were retrieved from the Therapeutic Target Database (TTD) and the complete drug (inhibitor) information was retrieved from Drug Bank (Fig. 2). Sorafenib is an approved drug for pancreatic cancer $[11,16]$.

\section{(iii)Retrieval of Structural Analogs of Sorafenib}

Using PubChem Database, 265 structural analogs of Sorafenib were retrieved, out of which only 16 were involved in the bioassays i.e. whose activities were known. The structures of all these structural analogs were downloaded in the 3-D SDF file formats and converted to mol2 format using Mercury (Version 2.3) software.

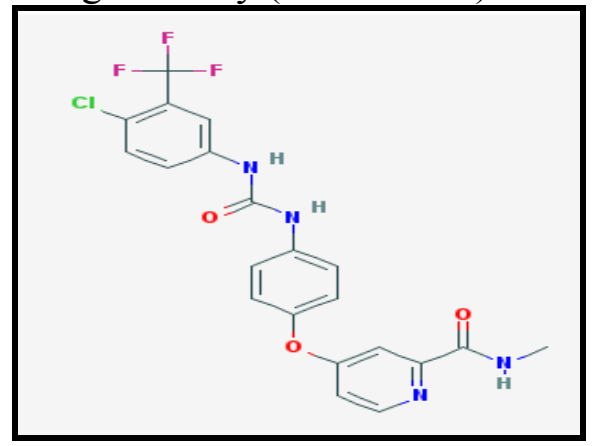

PubChem CID:216239;

Therapeutic Target Database TTDS00346

Drug Bank DAP00006.

N-(4-Chloro-3-(trifluoromethyl)phenyl)-N'-

(4-(2-(N-methylcarbamoyl)-4-pyridyloxy)phenyl) urea

SMILES: $\mathrm{CNC}(=\mathrm{O}) \mathrm{C} 1=\mathrm{NC}=\mathrm{CC}(=\mathrm{C} 1) \mathrm{OC} 2=\mathrm{CC}=\mathrm{C}(\mathrm{C}=\mathrm{C} 2)$

$\mathrm{NC}(=\mathrm{O}) \mathrm{NC} 3=\mathrm{CC}(=\mathrm{C}(\mathrm{C}=\mathrm{C} 3) \mathrm{Cl}) \mathrm{C}(\mathrm{F})(\mathrm{F}) \mathrm{F}$

Fig 2: 2-D conformer of Sorafenib from PubChem 
(iv) Identification of potential off-targets of Sorafenib:

The macromolecules surface similarity detection software MEDIT SA MED-SuMo identified various protein kinases as possible off-targets of Sorafenib using B-Raf/Sorafenib complex available in the PDB.

\section{(v) Docking Studies}

Docking was performed using FlexX (Version 2.02). It is a docking program based on scan interaction site algorithm for predicting protein-ligand interactions. Docking of Sorafenib and its 16 structural analogs with B-Raf (PDB ID: 1UWH) was performed followed by the docking of Sorafenib and the potential off-targets shortlisted with PDB IDs- 2O5C, 3BE2, 3CS9 and 1T46.

\section{RESULTS AND DISCUSSION}

B-Raf is a multi- drug target serine/threonine protein kinase, involved in the transduction of mitogenic signals from the cell membrane to the nucleus [17]. Protein kinases are excellent drug targets with structurally conserved catalytic domains. Despite the high sequence homology, protein kinases have selectivity for specific protein substrates conferred by localization, timing of activation and sequence specificity encoded in the substrate binding domain. Mutated B-Raf causes overactive downstream signaling via MEK and ERK which leads to excessive cell proliferation and survival, independent of growth factors causing the diseased state of the cell [18].

In the present study, Sorafenib was selected as it is a novel bi-aryl urea that is a potent inhibitor of Raf-1, a member of the RAF/MEK/ERK signaling pathway [19]. Sorafenib has been approved for the treatment of number of cancers such as advanced renal cell carcinoma (primary kidney cancer), advanced hepatocellular carcinoma (primary liver cancer), and pancreatic cancer $[11,12]$. In cellular mechanistic assays, Sorafenib demonstrates inhibition of the mitogen-activated protein kinase pathway [20] in colon, pancreatic, and breast tumor cell lines expressing wild-type or mutant B-Raf [21].

Figures 3 and 4 show the FlexX docking results of Sorafenib and B-Raf (PDB ID:1UWH) and its visualization in UCSF Chimera (Version 1.6), respectively. These results showing the binding pocket interacting residues of B-Raf are in conformity with the results of Puxeddu et al. [22]. They reported that crystallization of Sorafenib with wild-type B-Raf and the oncogenic V599E B-Raf showed that the pyridyl ring of Sorafenib directly interacts with amino acids-Leu 513, Thr 528, Gly 533, Cys 531, Phe 594 and Phe 582 in the binding pocket and the urea moiety forms several hydrogen bonds with the enzyme.

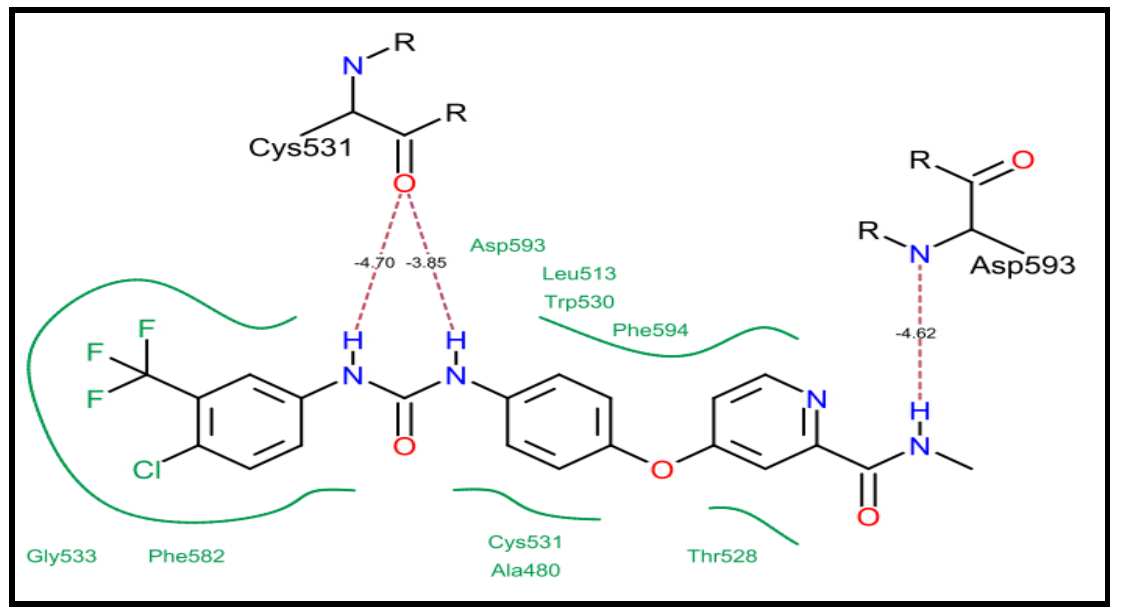

Fig 3: Docking of B-Raf and Sorafenib obtained using FlexX 


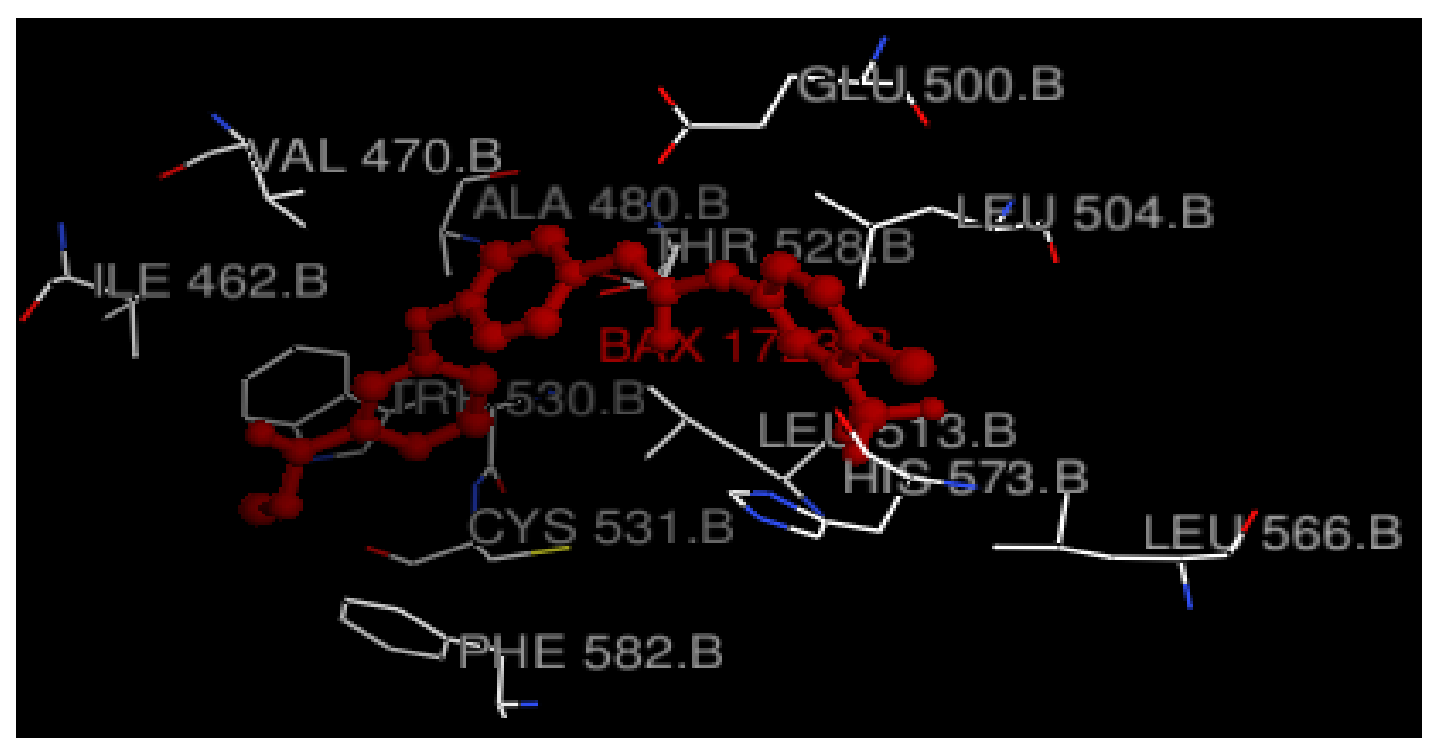

Fig 4: Interacting residues in the binding site of B-Raf docked with Sorafenib visualized using UCSF Chimera

Docking of Sorafenib and all its 16 structural analogs with B-Raf (PDB ID: IUWH) was done using FlexX (Table 1). Docking scores of some of the ligands were found to be similar but on analysis of various parameters like- clashes (stearic hindrance) \& lipophilic contact are, it was observed that Sorafenib had the best potency along with the analog 13 i.e. CID:10151557 which also has minimum number of clashes, low lipophilic score and high match score as shown in Table 1 and Fig. 5.

Various side effects of Sorafenib like fatigue and asthenia and pain in (mouth, bone, and tumor) have been reported by FDA which might be due to the biding of Sorafenib to its off-targets [8]. Sorafenib has been reported to demonstrate significant activity against several receptor tyrosine kinases involved in neovascularization and tumor progression, including VEGFR-2, VEGFR-3, platelet-derived growth factor receptor beta, Flt-3, and c-KIT [23]. The off-targets of Sorafenib that were retrieved using MEDIT SA MED-SuMo and were validated through literature are given in Table 2.

\begin{tabular}{|l|l|c|c|c|c|c|c|}
\hline Table 1: Docking scores of Sorafenib and its structural analogs with B-Raf using FlexX. \\
\hline & Ligand & Score & Match & Lipo* & Amb* & Clash* & Rot* \\
\hline Sorafenib & 216239 & -26.55 & -18.10 & -11.95 & -9.25 & 3.17 & 4.2 \\
\hline Ana1* & 51354603 & -21.63 & -13.72 & -17.09 & -9.02 & 4.41 & 8.4 \\
\hline Ana2 & 49830591 & -26.42 & -15.96 & -13.96 & -8.58 & 2.48 & 4.2 \\
\hline Ana3 & 44565731 & -26.79 & -16.41 & -14.87 & -10.49 & 5.37 & 4.2 \\
\hline Ana4 & 44565730 & -27.10 & -16.48 & -17.08 & -9.52 & 6.38 & 4.2 \\
\hline Ana5 & 44565710 & -26.21 & -16.66 & -13.39 & -8.32 & 2.57 & 4.2 \\
\hline Ana6 & 44420332 & -21.35 & -15.43 & -13.64 & -8.77 & 5.51 & 5.6 \\
\hline Ana7 & 44378490 & -27.21 & -15.07 & -20.78 & -8.30 & 5.94 & 5.6 \\
\hline Ana8 & 11503895 & -19.47 & -13.37 & -16.96 & -7.29 & 4.35 & 8.4 \\
\hline Ana9 & 10311642 & -26.45 & -15.77 & -14.46 & -9.44 & 3.62 & 4.2 \\
\hline Ana10 & 10217682 & -24.59 & -17.53 & -13.31 & -9.38 & 4.64 & 5.6 \\
\hline Ana11 & 10195599 & -25.24 & -17.45 & -13.98 & -8.54 & 3.74 & 5.6 \\
\hline Ana12 & 10152022 & -22.30 & -17.88 & -13.22 & -9.08 & 8.29 & 4.2 \\
\hline Ana13 & 10151557 & -26.56 & -20.13 & -11.65 & -9.06 & 4.69 & 4.2 \\
\hline Ana14 & 10128955 & -28.87 & -23.87 & -14.58 & -12.4 & 8.28 & 8.4 \\
\hline Ana15 & 10128380 & -22.66 & -17.95 & -11.50 & -8.16 & 2.56 & 7.0 \\
\hline Ana16 & 6605249 & -24.55 & -16.17 & -11.49 & -9.22 & 2.74 & 4.2 \\
\hline *Ana- Analog; Lipo- Lipophilic; Amb- Ambiguities; Clash- Clashes; Rot- Rotation \\
\hline
\end{tabular}



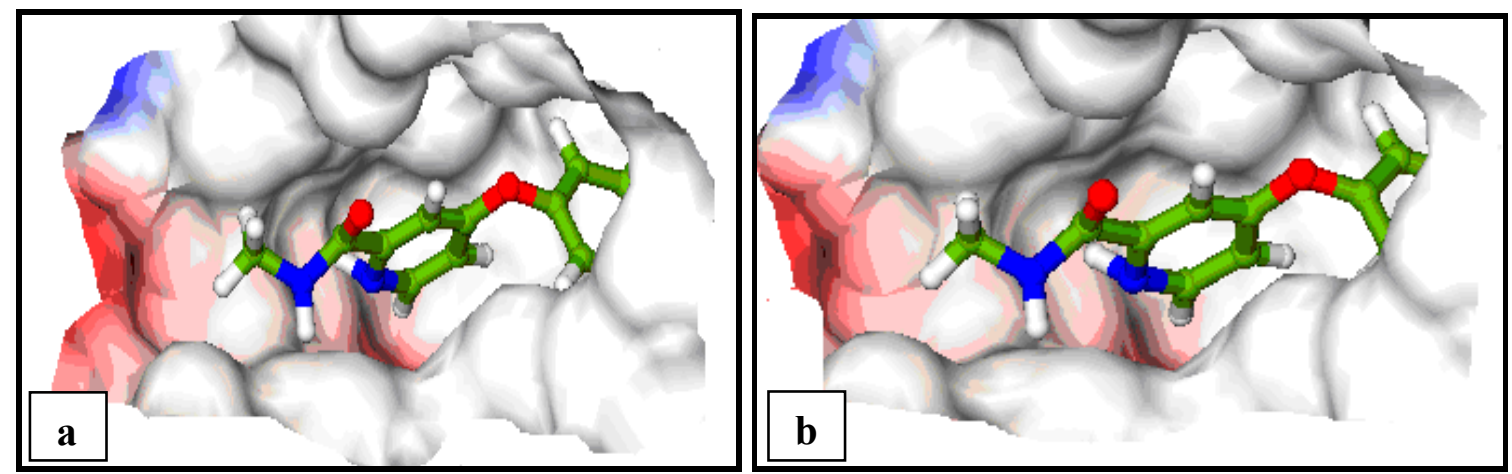

Fig 5: Docking of (a) Sorafenib (b) Analog 13 CID:10151557 with B-Raf protein (PDB ID:1UWH)

\begin{tabular}{|c|l|}
\hline \multicolumn{2}{|c|}{ Table 2: Functions of Sorafenib's Off-Targets reported on PubMed [8] } \\
\hline PDB ID & \multicolumn{1}{c|}{ FUNCTIONS } \\
\hline 205C & Angiopoietin receptor i.e. trafficking protein particlecomplex subunit 23 \\
\hline 3BE2 & Vascular endothelial growth factor tyrosine kinase \\
\hline 3CS9 & Bce-Abl Tyrosine kinase oncogene causing CML \\
\hline 1T46 & CKit receptor protein tyrosine kinase \\
\hline
\end{tabular}

To investigate the cross reactivity of Sorafenib with its off-targets, Sorafenib was individually docked against all the off-targets given in Table 2 using FlexX. The docking scores of Sorafenib with its target- B-Raf and its off-targets are given in Table 3.

It was seen that VEGFR receptor (PDB ID: 3BE2) is a potential off-target of Sorafenib due to a high value of its cumulative docking score, low lipophilic and minimum clashes with the drug. The binding site residues- Cys, Leu, Thr and Phe, that interact with Sorafenib were found to be similar in binding pockets of B-Raf [22] and VEGFR receptor (Fig. 6) though the shapes of the binding pockets differed and consequently the interacting residue numbers.

\begin{tabular}{|c|c|c|c|c|c|c|}
\hline Table 3: Docking scores of Sorafenib with B-Raf and its off-targets using FlexX. \\
\hline PDB ID & Score & Match & Lipo & Amb & Clash & Rot \\
\hline 1UWH & -26.55 & -18.10 & -11.9 & -9.20 & 3.17 & 4.2 \\
\hline 2OSC & -16.83 & -13.50 & -9.20 & -5.50 & 1.80 & 4.2 \\
\hline 3BE2 & -38.42 & -29.01 & -14.75 & -7.55 & 3.20 & 4.2 \\
\hline 3CS9 & -41.17 & -30.55 & -16.89 & -9.20 & 5.90 & 4.2 \\
\hline 1T46 & -33.11 & -24.38 & -13.61 & -9.84 & 5.12 & 4.2 \\
\hline
\end{tabular}

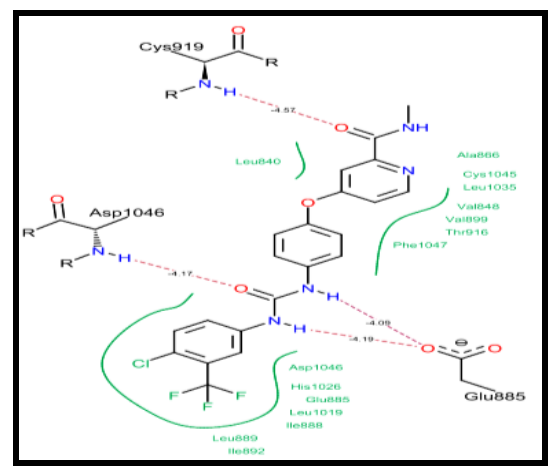

Fig 6: Interacting residues of VEGFR docked with Sorafenib. 


\section{CONCLUSION}

Thus it was concluded that Vascular endothelial growth factor tyrosine kinase receptor (VEGFR) is a potential off-target for the drug Sorafenib being responsible for its reported side effects in chemotherapy.

\section{REFERENCES}

[1] J. Ling, Y. Kang, R. Zhao, Q. Xia, D.F. Lee , Z. Chang, J. Li , B. Peng, J.B. Fleming, H. Wang, J. Liu, I.R. Lemischka, M.C. Hung, P.J. Chiao, Kras (G12D)-Induced IKK2/ $\beta / N F-\kappa B$ Activation by IL-1 $\alpha$ and p62 Feed forward Loops Is Required for Development of Pancreatic Ductal Adenocarcinoma. Cancer Cell 21[2012] 105-20.

[2] D. Singh, G. Upadhyay, R.K. Srivastava, S. Shanker, Recent advances in pancreatic cancer:biology, treatment and prevention, Biochimica et Biophysica Acta (BBA)- Reviews on Cancer 1856[1] (2015) 12-27.

[3] L. Liu, Y. Cao, C. Chen, X. Zhang, A. McNabola, D. Wilkie, S. Wilhelm, M. Lynch, C. Carter, Sorafenib Blocks the RAF/MEK/ERK Pathway, Inhibits Tumor Angiogenesis, and Induces Tumor Cell Apoptosis in Hepatocellular Carcinoma Model PLC/PRF/5, Cancer Res. 66 (2006) 11851.

[4] M. Karbowniczek, G.P. Robertson, E.P. Henske, Rheb Inhibits C-Raf Activity and B-Raf/CRaf Heterodimerization, The Journal of Biological Chemistry, 281(2006) 25447-25456.

[5] P.T.C Wan, M.J. Garnett, S.M. Roe, S. Lee, D. Niculescu-Duvaz, V.M. Good, C.M. Jones, C.J. Marshall, C.J. Springer, D. Barford, R. Marais; Cancer Genome Project, Mechanism of activation of the RAF-ERK signaling pathway by oncogenic mutations of B-RAF, Cell $116[6]$ (2004) 855-867.

[6] S. Benlloch, A. Paya, C. Alenda, X. Bessa, M. Andreu, R. Jover, A. Castells, X. Llor, F.I. Aranda, B. Massutí, Detection of BRAF V600E mutation in colorectal cancer: comparison of automatic sequencing and real-time chemistry methodology, J. Mol. Diagn. 8 [5] (2006) $540-3$.

[7] Y.H. Tan, Y. Liu, K.W. Eu, P.W. Ang, W.Q. Li, M. Salto-Tellez, B. Iacopetta, R. Soong, Detection of BRAF V600E mutation by pyrosequencing, Pathology 40[3] (2008) 295-8.

[8] M.H. Chen, R. Kerkelä, T. Force, Mechanisms of cardiac dysfunction associated with tyrosine kinase inhibitor cancer therapeutics, Circulation 118 (2008) 84-95.

[9] G. Sithanandam, W. Kolch, F.M. Duh, U.R. Rapp, Complete coding sequence of a human B-Raf cDNA and detection of B- Raf protein kinase with isozyme specific antibodies, Oncogene 5[12] (1990) 1775-80.

[10] M.N. Stein and K.T. Flaherty, CCR drug updates: Sorafenib and sunitib in renal cell carcinoma. Clin. Cancer Res. 13 (2007) 3765-3770.

[11] S. Cascinu, R. Berardi, A. Sobrero, P. Bidoli, R. Labianca, S.Siena, D. Ferrari, S. Barni, E.Aitini, V. Zagonel, F. Caprioni, F. Villa, S. Mosconi, L. Faloppi, G. Tonini, C. Boni, P. Conte, F.D. Costanzo, Sorafenib does not improve efficacy of chemotherapy in advanced pancreatic cancer: A GISCAD randomized phase II study, Digestive and Liver Disease 46[2] (2014) 182-186.

[12] O. Abdel-Rahman and M. Fouad, Sorafenib-based combination as a first line of treatment fot advanced hepatocellular carcinoma: A systematic review of the literature, Clinical Reviews in Oncology/Hematology 91[1] (2014) 1-8.

[13] J.A. Gollob, S. Wilhelm, C. Carter, S.L. Kelley, Role of Raf kinase in cancer: therapeutic potential of targeting the Raf/MEK/ERK signal transduction pathway, Seminars in oncology 33[4] (2006) 392-406.

[14] H. Namba, M. Nakashima, T. Hayashi, N. Hayashida, S. Maeda, T.I. Rogounovitch, A. Ohtsuru, V.A. Saenko, T. Kanematsu, S. Yamashita, Clinical implication of hot spot BRAF mutation, V599E, in papillary thyroid cancers, J. Clin. Endocrinol. Metab. 88[9] (2003) 4393-7. 
[15] T. Ahmad and T. Eisen, Kinase inhibition with BAY 43-9006 in renal cell carcinoma, Clin. Cancer Res. 10 (2004) 6388-92.

[16] J. Tsai, J.T. Lee, W. Wang, J. Zhang, H. Cho, S. Mamo, R. Bremer, S. Gillette, J. Kong, N.K. Haass, K. Sproesser, L. Li, K.S. Smalley, D. Fong, Y.L. Zhu, A. Marimuthu, H. Nguyen, B. Lam, J. Liu, I. Cheung, J. Rice, Y. Suzuki, C. Luu, C. Settachatgul, R. Shellooe, J. Cantwell, S.H. Kim, J. Schlessinger, K.Y. Zhang, B.L. West, B. Powell, G. Habets, C. Zhang, P.N. Ibrahim, P. Hirth, D.R. Artis, M. Herlyn, G. Bollag, Discovery of a selective inhibitor of oncogenic B-Raf kinase with potent antimelanoma activity, Proc. Natl. Acad. Sci. U.S.A. 105[8] (2008) 3041-6.

[17] M.J. Garnett and R. Marais, Guilty as charged: B-Raf is a human oncogene, Cancer Cell 6[4] (2004) 313-9.

[18] J.L. Maldonado, J. Fridlyand, H. Patel, A. N. Jain, K. Busam, T. Kageshita, T. Ono, D.G. Albertson, D. Pinkel, B.C. Bastian, Determinants of BRAF mutations in primary melanomas, J. Natl. Cancer Inst. 95 [24] (2003)1878-90.

[19] H. Davies, G.R. Bignell, C. Cox, P. Stephens, S. Edkins, S. Clegg, J. Teague, H. Woffendin, M.J. Garnett, W. Bottomley, N. Davis, E. Dicks, R. Ewing, Y. Floyd, K. Gray, S. Hall, R. Hawes, J. Hughes, V. Kosmidou, A. Menzies, C. Mould, A. Parker, C. Stevens, S. Watt, S. Hooper, R. Wilson, H. Jayatilake, B.A. Gusterson, C. Cooper, J. Shipley, D. Hargrave, K. Pritchard-Jones, N. Maitland, G. Chenevix-Trench, G.J. Riggins, D.D. Bigner, G. Palmieri, A. Cossu, A. Flanagan, A. Nicholson, J.W. Ho, S.Y. Leung, S.T. Yuen, B.L. Weber, H.F. Seigler, T.L. Darrow, H. Paterson, R. Marais, C.J. Marshall, R. Wooster, M.R. Stratton, P.A. Futreal, Mutations of the BRAF gene in human cancer, Nature 417 (2002) 949-54.

[20] A.J. King, D.R. Patrick, R.S. Batorsky, M.L. Ho, H.T. Do, S.Y. Zhang, R. Kumar, D.W. Rusnak, A.K. Takle, D.M. Wilson, E. Hugger, L. Wang, F. Karreth, J.C. Lougheed, J.Lee, D. Chau, T.J. Stout, E.W. May, C.M. Rominger, M.D. Schaber, L. Luo, A.S. Lakdawala, J.L. Adams, R.G. Contractor, K.S. Smalley, M. Herlyn, M.M. Morrissey, D.A. Tuveson, P.S. Huang, Demonstration of a genetic therapeutic index for tumors expressing oncogenic BRAF by the kinase inhibitor SB-590885. Cancer Res. 66[23] (2006) 11100-5.

[21] H. Gear, H. Williams, E.G. Kemp, F. Roberts, BRAF mutations in conjunctival melanoma, Invest. Ophthalmol. Vis. Sci. 45[8] (2004) 2484-8.

[22] E. Puxeddu, S. Moretti, R. Elisei, C. Romei, R. Pascucci, M. Martinelli, C. Marino, N. Avenia, E.D. Rossi, G. Fadda, A. Cavaliere, R. Ribacchi, A. Falorni, A. Pontecorvi, F. Pacini, A. Pinchera, E. Santeusanio, BRAF(V599E) mutation is the leading genetic event in adult sporadic papillary thyroid carcinomas, J. Clin. Endocrinol. Metab. 89[5] (2004) 241420.

[23] A. Jayanthan, D. Bernoux, P. Bose, K. Riabowol, A. Narendran, Multi-tyrosine kinase inhibitors in preclinical studies for pediatric CNS AT/RT: Evidence for synergy with Topoisomerase-I inhibition, Cancer Cell International, 11 (2011) 44. 